\title{
Reconstructing the glacier contribution to sea-level rise back to 1850
}

\author{
J. Oerlemans ${ }^{1}$, M. Dyurgerov ${ }^{2}$, and R. S. W. van de Wal ${ }^{1}$ \\ ${ }^{1}$ Institute for Marine and Atmospheric Research, Utrecht University, Princetonplein 5, Utrecht 3584CC, The Netherlands \\ ${ }^{2}$ Department of Physical Geography and Quaternary Geology, Stockholm University, 10654 Stockholm, Sweden
}

Received: 5 June 2007 - Published in The Cryosphere Discuss.: 27 June 2007

Revised: 16 November 2007 - Accepted: 22 November 2007 - Published: 6 December 2007

\begin{abstract}
We present a method to estimate the glacier contribution to sea-level rise from glacier length records. These records form the only direct evidence of glacier changes prior to 1946, when the first continuous mass-balance observations began. A globally representative length signal is calculated from 197 length records from all continents by normalisation and averaging of 14 different regions. Next, the resulting signal is calibrated with mass-balance observations for the period 1961-2000. We find that the glacier contribution to sea level rise was $5.5 \pm 1.0 \mathrm{~cm}$ during the period $1850-2000$ and $4.5 \pm 0.7 \mathrm{~cm}$ during the period 1900-2000.
\end{abstract}

\section{Introduction}

A recent compilation of tide-gauge data has shown that during the period $1870-2004$ sea level rose by $\approx 19.5 \mathrm{~cm}$ (Church and White, 2006). Thermal expansion of ocean water, changes in terrestrial storage of water, melting of smaller ice caps and glaciers, and possible long-term imbalances of the mass budgets of the Greenland and Antarctic ice sheets have been listed as the most important processes contributing to the observed sea level rise. In the IPCC2001 report the glacier contribution is estimated to have been $0.3 \pm 0.1 \mathrm{~mm} \mathrm{a}^{-1}$ over the 20th century. The glacier contribution has not been measured directly, but was inferred from a combination of modelling studies and mass-balance observations during the past few decades. In the IPCC2007 report the glacier contribution to sea-level rise is estimated as $0.50 \pm 0.18 \mathrm{~mm} \mathrm{a}^{-1}$ for the period 1961-2003 and $0.77 \pm 0.22 \mathrm{~mm} \mathrm{a}^{-1}$ for the period 1993-2003. This is largely based on compilations of mass-balance data (Dyurgerov and Meier, 2005; Kaser et al., 2006).

A significant part of the observed-sea-level rise over the last century cannot be explained by current estimates of ther-

Correspondence to: J. Oerlemans

(j.oerlemans@phys.uu.nl) mal expansion and changes in the cryosphere. It is therefore important to fully exploit the existing data on changes in the cryosphere, including those referring to glacier changes prior to 1961. In this paper an attempt is made to use data on glacier length for an assessment of changes in glacier volume since the middle of the 19th century. Unless stated otherwise, throughout this paper we mean by "glacier contribution" the contribution to sea-level change from all glaciers and ice caps outside the large ice sheets of Greenland and Antarctica. Included are the glaciers and ice caps on Greenland and Antarctica which are not part of or attached to the main ice sheets (as defined in Dyurgerov and Meier, 2005).

Very few attempts have actually been made to calculate the glacier contribution over the past 100 years or longer. Meier (1984) estimated that glaciers have contributed $2.8 \mathrm{~cm}$ to sealevel rise in the period 1900-1961. His approach starts with an analysis of mass balance data for a few decades, including a scaling procedure in which glaciers with a larger mass turnover have lost more ice. The extrapolation backwards in time until 1900 is based on 25 glacier records.

Zuo and Oerlemans (1997) took a different approach. The contribution of glacier melt to sea-level change since AD 1865 was estimated on the basis of modelled sensitivities of glacier mass balance to climate change and historical temperature data. Calculations were done in a regionally differentiated manner to overcome the inhomogeneity of the distribution of glaciers. A distinction was made between changes in summer temperature and in temperature over the rest of the year. In this way, Zuo and Oerlemans (1997) arrived at a number of $2.7 \pm 1.0 \mathrm{~cm}$ for the sea-level contribution for the period 1865-1990.

The study by Meier (1984) was based on a very limited data set. Zuo and Oerlemans (1997) faced the problem that their results depended strongly on the choice of initial state, and also that reliable precipitation data back to 1865 do not exist (implying that only temperature forcing could be used).

Published by Copernicus Publications on behalf of the European Geosciences Union. 


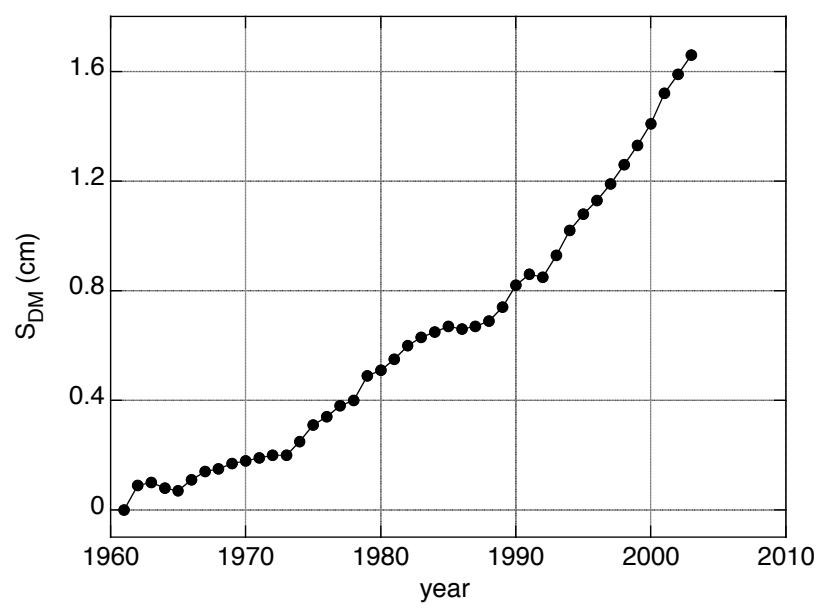

Fig. 1. Cumulative contribution of glaciers to sea-level rise (SL) as estimated by Dyurgerov and Meier (2005) from a compilation of mass-balance observations.

A comprehensive analysis of mass-balance data was carried out by Dyurgerov and Meier (2005). They compiled all available mass-balance data, grouped them into regions, and arrived at an estimate of the glacier contribution to sea-level rise for the period 1961-2003. However, the number of long series ( $>3$ decades) of direct mass-balance observations is small and does not provide a good global coverage.

Glacier length records, on the other hand, have a better global coverage and are less biased towards small glaciers. Most importantly, glacier length records go much further back in time and thus form the only source of observational information from which a sea-level contribution over the past 100 or 150 years can be estimated. It would thus be beneficial if the compilation of mass balance data could be combined with glacier-length records to arrive at a best estimate of the glacier contribution to sea-level rise. In this paper we report on a relatively simple approach along this line. Our basic assumption is that, when averaged over a sufficient number of glaciers, changes in glacier volume can be related to changes in glacier length. Scaling theory (Bahr et al., 1997; Van de Wal and Wild, 2001) provides some support for this assumption, at least when larger time scales ( $>10$ a) are considered. A normalised and scaled global proxy for ice volume is then calibrated against the mass balance data and subsequently used to obtain the glacier contribution to sea-level rise since 1850.

Quantitative studies in which all glaciers of the world are considered together are difficult, and therefore not frequently done. Glaciers exist in all sizes and shapes, and there are so many that it is impossible to model each glacier separately. Yet in one way or another one would like to use the vast amount of data on glacier fluctuations that is currently available. The approach taken here is rather pragmatic, including only a minimum of glacier mechanics. Nevertheless, it pro-

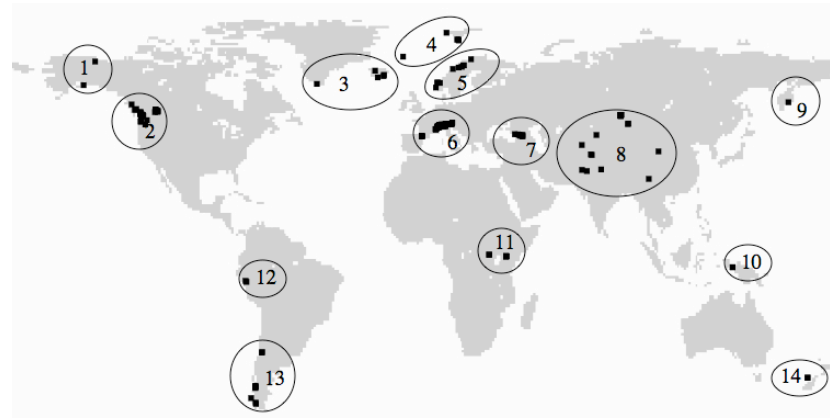

Fig. 2. Glaciers for which length records are available. There are 197 records in the data set, representing 14 regions: (1) Alaska, (2) Rocky Mountains, (3) South Greenland and Iceland, (4) Jan Mayen and Svalbard, (5) Scandinavia, (6) Alps and Pyrenees, (7) Caucasus, (8) Central Asia, (9) Kamchatka, (10) Irian Jaya, (11) Central Africa, (12) Tropical Andes, (13) Southern Andes, (14) New Zealand. In many cases the distance between glaciers is so small that they appear as a single square on the map (e.g. the two squares in central Africa represent six glaciers). The number of records in each region is given in Table 1 .

vides more than just qualitative statements about the large changes seen on glaciers and the consequences for sea level.

\section{Data}

The data used in this study are: (i) Annual change in glacier volume estimated by Dyurgerov and Meier (2005) for the period 1961-2003; (ii) Glacier length records (Oerlemans, 2005).

The result of the study by Dyurgerov and Meier (2005) is shown in Fig. 1. The total contribution by glaciers to sealevel rise amounts to about $1.6 \mathrm{~cm}$ over a 40 -yr period. Compared to the estimates mentioned above for a $100-\mathrm{yr}$ period, this is a large number. Figure 1 also suggests that the rate at which glaciers lose mass is increasing. It should be noted that in the analysis of Dyurgerov and Meier (2005) conventional mass-balance data have been complemented by direct measurements of changes in glacier volume, notably for Alaska (Ahrendt et al., 2002) and Patagonia (Rignot et al., 2003).

The dataset on glacier length used in this study is an extension of the one used in Oerlemans (2005). A number of records has been updated, and 28 records were added, some from remote places like Kamchatka, Alaska and the southern Andes. The total number of records is 197. Although there is a reasonable coverage of the land masses (Fig. 2), there are relatively few records from regions where a lot of ice is found (Alaska, islands of the Arctic Ocean). There are no records from the Canadian arctic, and only one from Greenland. In contrast, southern Europe (Pyrenees, Alps, Caucasus) has many records. Although there is an appreciable number of records from the Rocky Mountains, these are far from up-todate: some have their last data points in the 1980s. The mean 
Table 1. The 14 regions from which glacier length records are available. The weighting factors in the 6th coulmn have been used to calculate $\bar{L}_{w 14}$. From Dyurgerov and Meier (2005), slightly modified.

\begin{tabular}{|c|c|c|c|c|c|c|}
\hline & region & \# of records & area $\left(\mathrm{km}^{2}\right)$ & addition $\left(\mathrm{km}^{2}\right)$ & weight & comments \\
\hline 1 & Alaska & 2 & 74600 & 75000 & 0.244 & incl half of Canadian arctic \\
\hline 2 & Rocky Mountains & 28 & 49660 & 76433 & 0.206 & incl half of Canadian arctic \\
\hline 3 & S. Greenland, Iceland & 6 & 76200 & 11260 & 0.143 & incl small Greenland glaciers \\
\hline 4 & Jan Mayen, Svalbard & 4 & 36607 & 55779 & 0.151 & incl Russian Arctic islands \\
\hline 5 & Scandinavia & 10 & 2942 & & 0.005 & \\
\hline 6 & Alps and Pyrenees & 96 & 2357 & & 0.004 & \\
\hline 7 & Caucasus & 9 & 1428 & 48 & 0.002 & incl middle east \\
\hline 8 & Central Asia & 18 & 119850 & & 0.196 & \\
\hline 9 & Kamchatka & 1 & 905 & 3395 & 0.006 & incl Siberia \\
\hline 10 & Irian Jaya & 2 & 3 & & 0 & \\
\hline 11 & Central Africa & 7 & 6 & & 0 & \\
\hline 12 & Tropical Andes & 2 & 2200 & & 0.004 & \\
\hline 13 & Southern Andes & 10 & 23000 & 7000 & 0.038 & $\begin{array}{l}\text { not including bulk of } \\
\text { Antarctic islands }\end{array}$ \\
\hline \multirow[t]{2}{*}{14} & New Zealand & 2 & 1160 & & 0.002 & \\
\hline & TOTAL & 197 & 390920 & 228920 & 1 & \\
\hline
\end{tabular}

starting date of the 197 records is 1865 , the mean end date 1996. The set of length records is divided into 14 subsets (Fig. 2, Table 1). These subsets will be used later to calculate a globally representative glacier signal.

The backbone of the dataset comes from the World Glacier Monitoring Service (WGMS), the Swiss Glacier Monitoring Network, and the Norwegian Water and Energy Administration (NVE). Other sources are regular publications, expedition reports, websites, tourist flyers, and data supplied as personal communication. It is noteworthy that a large amount of data on glacier length has not been published officially. Only records with a first data point before 1950 are included. There are numerous records that start later, but these were not used because the purpose of this study is first of all to look at changes on a century time scale.

Many records have a rather irregular spacing of data points in time. The examples shown in Fig. 3 illustrate the significant coherence in glacier behaviour around the globe (this is representative for the entire dataset). World-wide retreat of glaciers starts around the middle of the 19th century. The curves differ in details like amplitude of the signal and fluctuations on a decadal time scale, but the overall picture is rather uniform.

To smooth the records and obtain interpolated values for individual years, Stineman-interpolation was applied (Stineman, 1984; see also Johannesson et al., 2006). After much experimentation with various interpolation schemes this turned out to be the best method. One of the advantages of the Stineman filtering is that no oscillations are generated around a peak in the raw data. The method is particularly good when the density of the data points in time varies strongly, as is the case with many glacier length records.

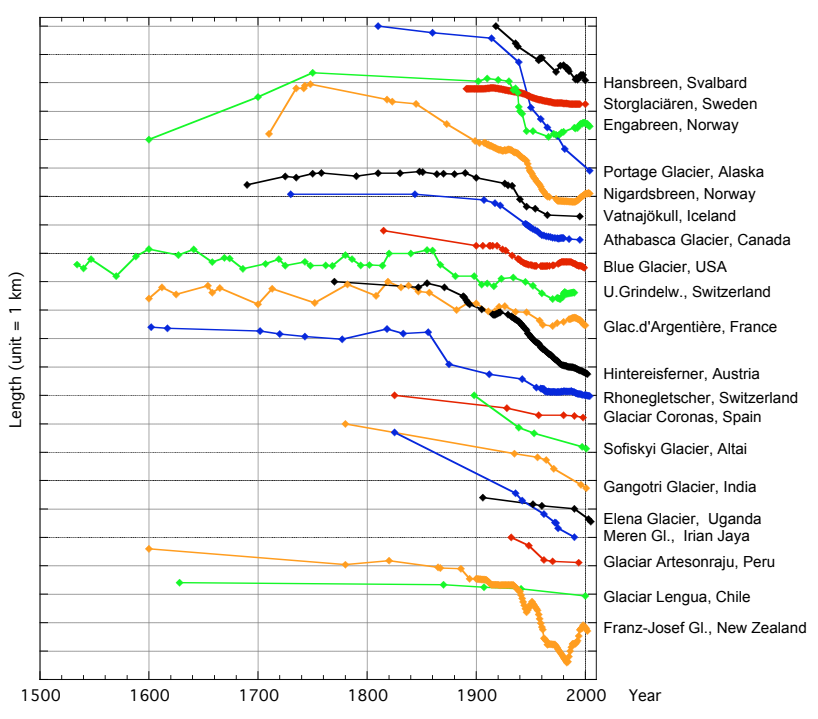

Fig. 3. Examples of glacier length records. Each symbol represents a data point. The records are ordered from north to south.

In this paper we consider glacier length relative to the 1950 length $\left(L_{1950}\right)$, and a normalised glacier length defined as

$L^{*}=\frac{L-L_{1950}}{L_{1950}}$

The normalised records will play a key role in the construction of a global proxy for changes in the volume of all glaciers and small ice caps. 

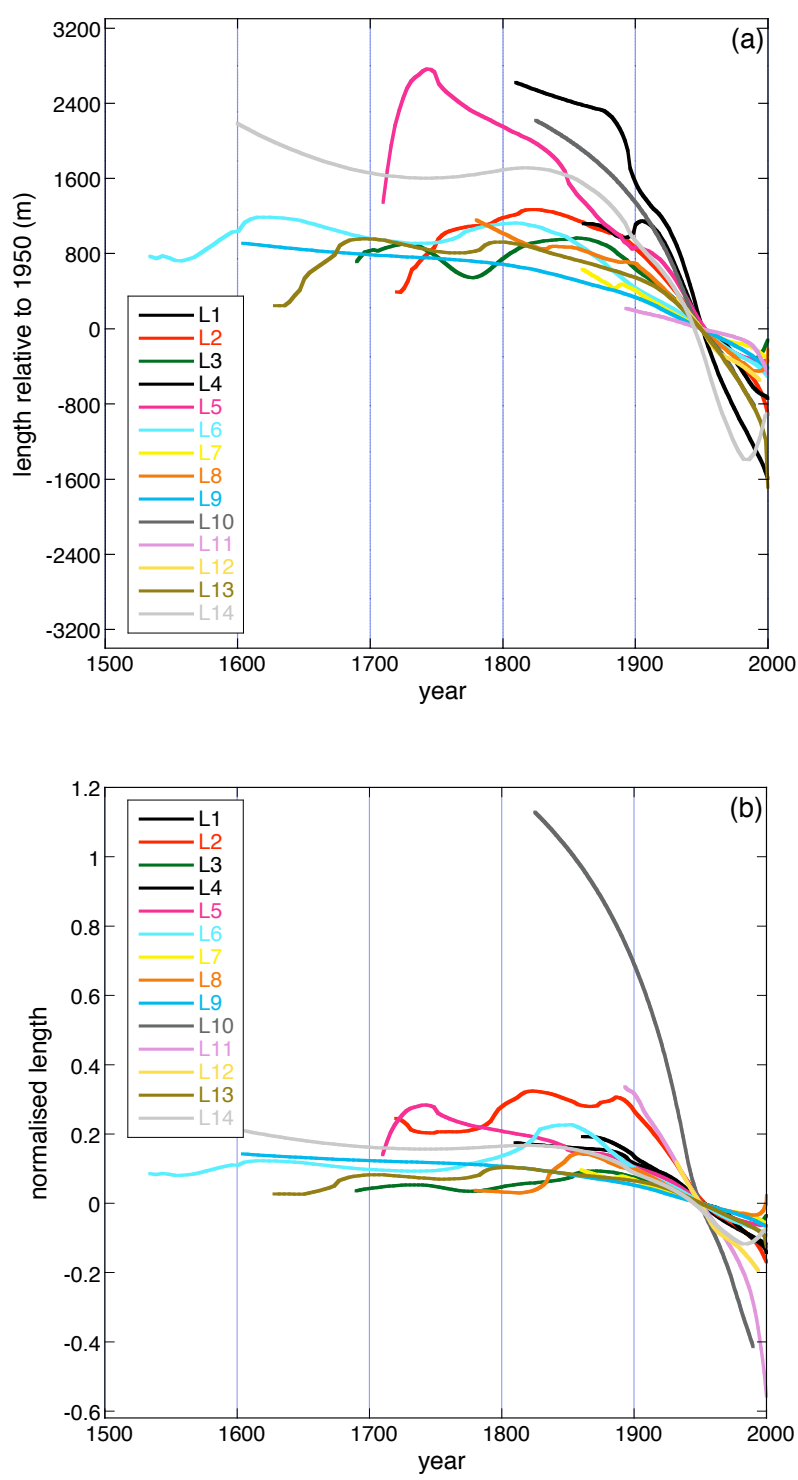

Fig. 4. (a) Stacked glacier length records for the different regions; in (b) the corresponding normalised records are shown. Region numbers are shown in Fig. 2.

\section{Stacked length records for regions}

To get an impression of glacier changes on a regional scale, stacked records were constructed from all available data in a particular region. Figure 4 shows the stacked glacier length after smoothing once more with the Stineman-filter. This smoothing is necessary because jumps in the stacked record are created when a "new" record enters the stack or when a record in the stack ends. It is evident from Fig. 4 that the differences among the regions are significant, but all stacked records show glacier retreat after the mid-19th century. This again illustrates the coherency of the glacier signal over the globe.

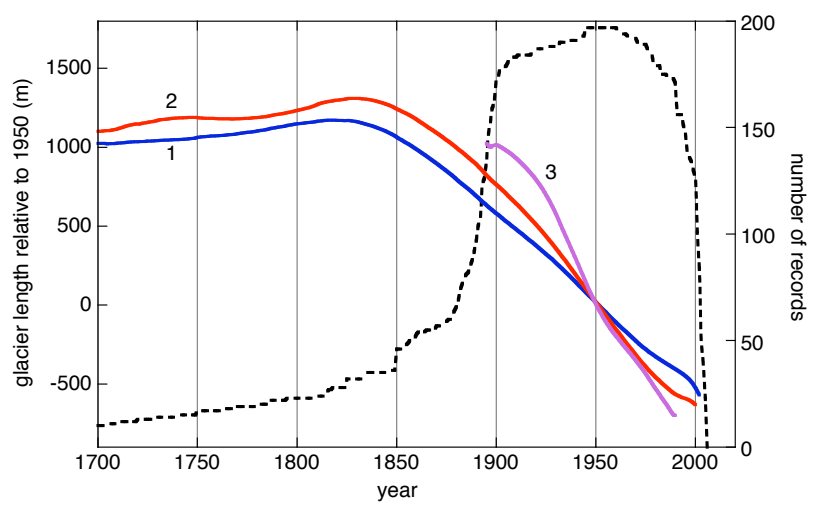

Fig. 5. The stacked global glacier length signal. The dashed line shows the number of data points (after interpolation of the records) for individual years (scale on right). The other curves show $\bar{L}(1$, blue), $\bar{L}_{14}\left(2\right.$, red) and $\bar{L}_{w 14}$ (3, purple).

In Fig. 4 there is a clear outlier: region 10 (Irian Jaya). The glaciers on Irian Jaya (Carstenz and Meren) have shown very strong relative retreats. But also the glaciers in central Africa (7 records) have become much smaller. It appears that the smallest relative changes have occurred in regions 3, 7 and 13 (S. Greenland/Iceland, Caucasus and Patagonia, respectively).

\section{The global signal}

It is clear that the majority of the records comes from regions where the ice cover is relatively small (notably the Alps and Rocky Mountains). The development of a globallyrepresentative proxy for ice volume therefore requires a weighting procedure that reduces the relative effect of datarich regions on the global signal. Here we achieve this by averaging the records of the 14 regions shown above. The result of this procedure is shown in Fig. 5.

The blue curve (1) in Fig. 5 refers to straighforward stacking of all available records $(\bar{L})$. As mentioned above, $\bar{L}$ is strongly biased towards the Alps, because about $30 \%$ of the records stems from this region. Giving equal weights to all regions $\left(\bar{L}_{14}\right)$ then yields the red curve (2) in Fig. 5. The differences between $\bar{L}$ and $\bar{L}_{14}$ are not very large, although the latter curve reveals a significantly larger glacier retreat during the period 1925-1975.

An other possible approach is to give different weights to the 14 regions, proportional to the glacierized areas in the regions $\left(\bar{L}_{w 14}\right)$. It can be argued that $\bar{L}_{w 14}$ would be a better proxy for total ice volume, because it removes the bias generated by more records in regions with smaller glaciers. The implication is that the signal is mainly determined by regions 1, 2, 3, 4 and 8 (see Table 1). It only makes sense to construct $\bar{L}_{w 14}$ for the period for which all these regions have meaningful records (1893-1989). 
To obtain weighting factors, the glacierised area not covered within the 14 regions is added over the 14 regions (Table 1, column labelled "Addition"). In fact, this procedure reveals the weakness of the data set on glacier fluctuations, namely, that little is known in some regions with large amounts of ice. Admittedly, the partition of glacier area over the 14 regions is rather arbitrary. For instance, half of the glacier area in the Canadian arctic was added to region 1 (Alaska), and half to region 2 (Rocky Mountains). Similarly, the records from Jan Mayen and Svalbard (region 4) are supposed to represent all glaciers and ice caps in the Arctic ocean. However, we stress already at this point that in the end the weighting factors were not used in calculating the sea-level contribution from glaciers, because the weighted length curve is very similar to the unweighted curve.

In Fig. 5 it can be seen that $\bar{L}_{w 14}$ follows the same pattern as $\bar{L}$ and $\bar{L}_{14}$, but the amplitude of the signal is larger. Records from regions 1, 2, 3, 4 and 8 are from glaciers larger than the average size in the dataset, and these tend to show larger fluctuations (presumably because the larger glaciers are flatter and therefore more sensitive to climate change, e.g. Oerlemans, 2005). It is therefore interesting to consider the normalised length records once more.

In analogy to the averaging procedure described above, $\bar{L}^{*}, \bar{L}_{14}^{*}$ and $\bar{L}_{w 14}^{*}$ have been calculated from the normalized length records (* refers to normalised). It should be noted that for a number of glaciers $L_{1950}$ is not very well known and has been obtained from interpolation on the nearest data points. However, this should hardly affect the results of the entire sample.

$\bar{L}^{*}, \bar{L}_{14}^{*}$ and $\bar{L}_{w 14}^{*}$ are shown in Fig. 6. The curves appear to be remarkably similar. This finding reflects the facts that (i) the behaviour of glaciers over the past few centuries has been coherent over the globe, and (ii) the relative change in glacier length has not been very different for smaller and larger glaciers. Nevertheless, the normalisation brings out more clearly the maximum glacier size between 1825 and 1875 , although it should be realised that the number of records starting before 1850 is small (Fig. 5).

It would perhaps be most appropriate to base a proxy for changes in glacier volume on $\bar{L}_{w 14}^{*}$. This would unfortunately imply that one cannot go further back in time than around 1900 . However, since $\bar{L}_{14}^{*}$ and $\bar{L}_{w 14}^{*}$ are very similar, it should be possible to base an ice volume proxy on $\bar{L}_{14}^{*}$. This will be worked out in the next section.

\section{Towards a proxy for glacier volume}

The next step to be made is to relate changes in glacier volume to changes in glacier length. Although general scaling theories have been developed for this (e.g. Bahr et al., 1997), it is not a priori clear how these should be applied. It appears that for many glaciers the loss of volume is first of all the result of a decreasing ice thickness and a decrease in area due

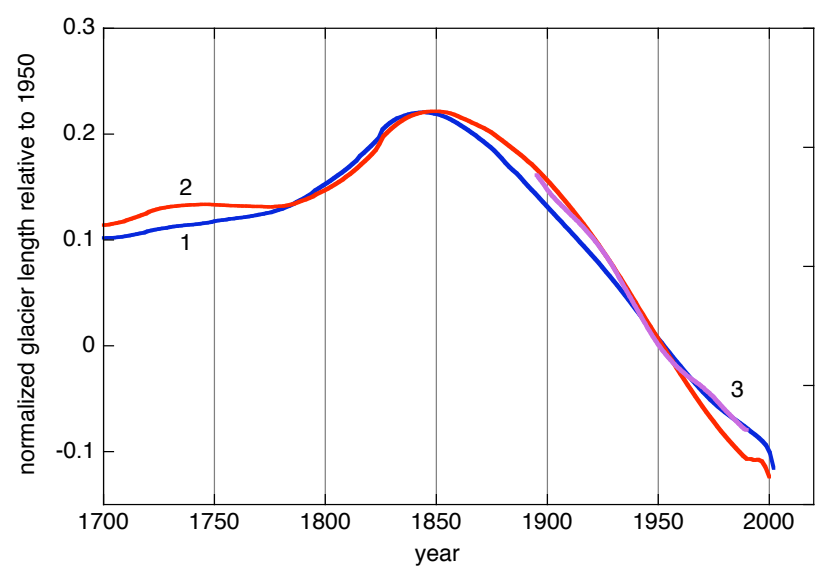

Fig. 6. As in Fig. 5 but now for normalized length records. The curves refer to $\bar{L}^{*}\left(1\right.$, blue), $\bar{L}_{14}^{*}(2$, red $)$ and $\bar{L}_{w 14}^{*}(3$, purple).

to a retreating glacier front. In many cases the adjustment of mean glacier width to a change in length is restricted by the geometry.

Here we use a relation that is in line with the scaling theory:

$\frac{H}{H_{\text {ref }}} \propto\left[\frac{L}{L_{\text {ref }}}\right]^{\alpha}$

where $H$ is mean ice thickness, $L$ glacier length or ice-cap radius and the subscript "ref" indicates a reference state. For a perfectly plastic glacier on a flat bed the mean thickness is proportional to the square root of the length, i.e. $\alpha=0.5$ (Weertman, 1961). Numerical models, based on the shallow ice approximation and integrated until steady states are reached, yield values in the 0.40 to 0.44 range, depending on the slope of the bed (Oerlemans, 2001; p. 69).

Next we write

$\frac{V}{V_{\text {ref }}} \propto\left[\frac{L}{L_{\text {ref }}}\right]^{\eta}$

$V$ denotes ice volume. Two extreme cases can be considered. In the first case it is assumed that a change in glacier length will not affect the glacier width. The change in volume is therefore only due to a change in mean thickness and a change in length, which implies that $\eta \approx 1.4$ to 1.5 . The second case refers to an ice cap which can move freely in all directions. The corresponding value of the exponent than is $\eta \approx 2.4$ to 2.5 . These values of $\eta$ should be compared to the scaling study of Bahr (1997). Based on the geometry of more than 300 glaciers, Bahr found that glacier area varies as $L^{1.6}$; the corresponding value of $\eta$ would be 2.0 to 2.1 (see also Barry, 2006).

Equation (3) refers to a single glacier. Now we postulate that a similar approach can be applied to the normalised global glacier signal $\bar{L}_{14}^{*}$ :

$V_{14}^{*}=\left(1+\bar{L}_{14}^{*}\right)^{\eta}$ 


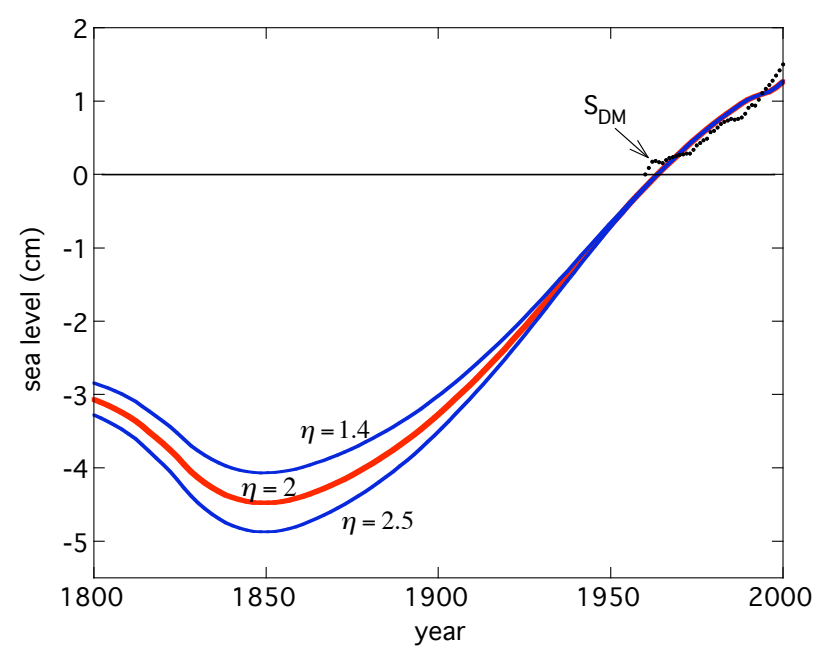

Fig. 7. Reconstruction of the glacier contribution to sea-level change for different values of $\eta$. The dots show the cumulative effect of global annual mass balance as calculated from observations by Dyurgerov and Meier (2005), see Fig. 1.

Note that according to this expression the nondimensional volume equals unity in the year 1950 for any value of the exponent $\eta . \quad V_{14}^{*}$ is now considered to be the best possible glacier volume proxy derived from the set of glacier length records, with $\eta$ within the 1.5 to 2.5 range, but probably close to 2.0 .

One may argue that a more accurate proxy for glacier volume could be obtained by estimating the volume of each individual glacier in the sample. However, for larger values of $\eta$ this leads to very large fluctuations because a few large glaciers may dominate the picture in an unrealistic way.

So far transient effects, i.e. an imbalance between the length and volume response to climate forcing, have not been considered. Experiments with numerical glacier models have been used to study characteristic response times for glacier length and volume (e.g. Greuell, 1992; Schmeits and Oerlemans, 1997; Oerlemans, 2001; Leysinger Vieli and Gudmundsson, 2004). In most studies it is found that glacier volume adjusts somewhat more quickly to climatic forcing than glacier length. However, the difference in response time depends on the particular geometry and is generally small (typically 10\%, Van de Wal and Wild, 2001). Radic et al. (2007) carried out a more explicit test on the performance of volume scaling, paying attention to transient effects. They found that scaling is a powerful tool even when changes in the climatic forcing are relatively fast. In conclusion, we feel that detailed studies support the use of $V_{14}^{*}$ as a proxy for changes in global glacier volume.

\section{The glacier contribution to sea-level rise}

To arrive at an estimate of the glacier contribution to sealevel change, $V_{14}^{*}$ is now calibrated with the compilation of mass balance data of Dyurgerov and Meier (2005), see Fig. 1. Dyurgerov and Meier (2005) estimated the change in glacier volume from mass-balance observations and extrapolated this to obtain an estimate of the annual contribution of glacier shrinkage to sea-level change. We denote the cumulative contribution to sea-level change by $S_{D M}$. Data are used for the period 1961-2000 (the "learning period" for $\left.V_{14}^{*}\right)$. The calibration is simply done by correlating $S_{D M}$ and $V_{14}^{*}$ for this period.

The correlation between $S_{D M}$ and $V_{14}^{*}$ is high and mainly stems from the linear trends during the period 1961-2000. For $\eta=1.4$ the correlation coefficient is 0.944 ; for $\eta=2$ it is 0.938 ; for $\eta=2.5$ it is 0.936 . On smaller time scales the relation between $S_{D M}$ and $V_{14}^{*}$ is weaker. For instance, around 1990 the glacier contribution to sea-level rise calculated from $V_{14}^{*}$ slightly declines, which is not seen in $S_{D M}$. However, one should realize that the set of glaciers for which length data are available is different from the set of glaciers on which $S_{D M}$ is based.

After having calibrated $V_{14}^{*}$ with $S_{D M}$, the glacier contribution to sea-level can be extended backwards in time. Since the number of glacier records is small before 1800 and after 2000, the result is only shown for the period 1800-2000. From Fig. 7 it is clear that the present estimate is large compared to numbers found in the literature: 5 to $6 \mathrm{~cm}$ for the period $1850-2000,4$ to $5 \mathrm{~cm}$ if the period $1900-2000$ is considered.

\section{Discussion}

Several test were carried out to see how sensitive the results are to the use of a different glacier length signal (e.g. deriving first hemispheric signals and then giving a larger weight to the Northern Hemisphere because the glacier area is much larger). It turns out that the sensitivity is small, which is a consequence of the rather coherent behaviour of glaciers over the globe (on a century time scale).

Figure 7 shows that the choice of the scaling parameter $\eta$ is not very critical. A range of parameter values of 1.4 to 2.5 is really a wide range, yet the differences in the calculated sealevel contribution are within $1 \mathrm{~cm}$ for the period 1850-2000 [It should be noted that for every value of $\eta$ the calibration with the mass-balance data is different].

We stress that the data on glacier area as summarized in Table 1 do not directly affect our estimate of the glacier contribution to sea-level rise. This information was only used to verify that $\bar{L}_{14}^{*}$ can be used to construct a proxy for ice volume variations.

The most critical aspect probably is the representativeness of the compilation of mass balance data. Fundamental to the 
present approach is the assumption that both $S_{D M}$ and $\bar{L}_{14}^{*}$ are signals that are truly globally representative. An extensive discussion on $S_{D M}$ has been given in Dyurgerov and Meier (2005). We note that the relative error in our estimate of the glacier contribution to sea-level rise is approximately proportional to the error in the glacier contribution calculated for the period 1961-2000. For instance, a 10\% error would then imply a $0.5 \mathrm{~cm}$ error in the calculated glacier contribution for the last hundred years. Altogether, our best estimates of the glacier contribution to sea-level rise are: for the period 1850-2000: $5.5 \pm 1.0 \mathrm{~cm}$; for the period 1900-2000: $4.5 \pm 0.7 \mathrm{~cm}$.

Compared to the number given in Zuo and Oerlemans (1997), namely $2.7 \mathrm{~cm}$ for the period 1865-1990, our current estimate is high. However, it should be remembered that the methodologies are quite different. In Zuo and Oerlemans (1997) changes in glacier volume were calculated from modelled mass-balance sensitivities and observed temperature data. Using glacier length records directly implies that all other effects (changes in precipitation, radiation, etc.) are implicitly included, although we still think that the temperature effect is most important.

As noted before, the normalisation of the glacier length records brings out the 1850 maximum more sharply (compare Figs. 5 and 6). The implication is a clear minimum in the sea-level contribution around 1850 (Fig. 7). However, we note that the number of records in the first half of the 19th century is small. Consequently, the significance of the minimum should not be overestimated and we restrict our conclusions about the glacier contribution to sea-level rise to the period after 1850 .

Edited by: A. Klein

\section{References}

Arendt, A., Echelmeyer, K., Harrison, W. D., Lingle, G., and Valentine, V.: Rapid wastage of Alaska glaciers and their contribution to rising sea level, Science, 297, 382-386, 2002.

Bahr, D. B.: Width and length scaling of glaciers, J. Glaciol., 43, 557-562, 1997.

Bahr, D. B., Meier, M. F., and Peckham, S. D.: The physical basis of glacier volume-area scaling, J. Geophys. Res., 102(B9), 20355 $20362,1997$.

Barry, R. G.: The status of research on glaciers and global glacier recession, Progr. Phys. Geogr., 30, 285-306, 2006.

Church, J. A. and White, N. J.: A $20^{t h}$ century acceleration in global sea-level rise, Geophys. Res. Lett., 33, L01602, doi:10.1029/2005GL024826, 2006.
Dyurgerov, M. B. and Meier, M. F.: Glaciers and the changing earth system: a 2004 snapshot, Occasional Paper No. 58, INSTAAR, University of Colorado, 2005.

Greuell, W.: Hintereisferner, Austria: mass-balance reconstruction and numerical modelling of the historical length variations, J. Glaciol., 38, 233-244, 1992.

IPCC-2001, Climate Change 2001: The Scientific Basis Contribution of Working Group I to the Third Assessment Report of the Intergovernmental Panel on Climate Change (IPCC), edited by: Houghton, J. T., Ding, Y., Griggs, D. J., Noguer, M., Van der Linden, P. J., and Xiaosu, D., Cambridge University Press, 2001.

IPCC-2007, Climate Change 2007: The Physical Science Basis, Contribution of Working Group I to the Fourth Assessment Report of the IPCC, Cambridge University Press, http://www.ipcc. $\mathrm{ch} /, 2007$.

Johannesson, T., Björnsson, H., and Grothendieck, G.: The Stinepack Package, Icelandic Meteorological Office, 2006.

Kaser, G., Cogley, J. G., Dyurgerov, M. B., Meier, M. F., and Ohmura, A.: Mass balance of glaciers and ice caps: Consensus estimates for 1961-2004, Geophys. Res. Lett., 33, L19501, doi:10.1029/2006GL027511, 2006.

Leysinger Vieli, G. J.-M. C. and Gudmundsson, G. H.: On estimating length fluctuations of glaciers caused by changes in climate forcing, J. Geophys. Res., 109, F01007, doi:10.1029/2003JF000027, 2004.

Meier, M. F.: Contribution of small glaciers to global sea-level, Science, 226, 1418-1421, 1984.

Oerlemans, J.: Glaciers and Climate Change, A.A. Balkema Publishers, 2001.

Oerlemans, J.: Extracting a climate signal from 169 glacier records, Science, 308, 675-677, doi:10.1126/science.1107046, 2005.

Radic, V., Hock, R., and Oerlemans, J.: Volume-area scaling approach versus flowline model in glacier volume projections, Ann. Glaciol., 46, 234-240, 2007.

Schmeits, M. J. and Oerlemans, J.: Simulation of the historical variations in length of the Unterer Grindelwaldgletscher, J. Glaciol., 43(143), 152-164, 1997.

Rignot, E., Rivera, A., and Casassa, G.: Contribution of the Patagonia Icefields of South America to global sea level rise, Science, 302, 434-437, 2003.

Stineman, R. W.: A consistently well-behaved method of interpolation, Creative Computing, July 1980, 54-57, 1980.

Van de Wal, R. S. W. and Wild, M.: Modelling the response of glaciers to climate change, applying volume-area scaling in combination with a high resolution GCM, Clim. Dyn., 18, 359-366, 2001.

Weertman, J.: Stability of ice-age ice-sheets, J. Geophys. Res., 66, 3783-3792, 1961.

Zuo, Z. and Oerlemans, J.: Contribution of glacier melt to sea-level rise since $\mathrm{AD}$ 1865: a regionally differentiated calculation, Clim. Dyn., 13, 835-845. 